\title{
Technology of Educational Electronic Publications' Quality Evaluation
}

\author{
Irina Kuznetsova ${ }^{1}$ \& Oleksandr Vovk \\ Kharkiv National University of Radioelectronics, UKRAINE \\ Faculty of Computer Science
}

Received 17 June 2019 • Revised 8 July 2019 • Accepted 13 July 2019

\begin{abstract}
Electronic publication (EP) is a complex product, which integrates the achievements of modern technology, content of the subject area and teaching methods, as well as design and artistic qualities. The transition from book reviewing to electronic publication reviewing is similar to the exit from the plane into multidimensional space. It's only natural that pedagogical, methodological and creative possibilities are much higher there, but it makes determining the technology and criteria for quality evaluation more difficult.
\end{abstract}

Keywords: technology, quality evaluation, electronic publication, educational electronic publication, expert evaluation, quality evaluation criteria.

\section{Introduction}

In modern society education's informatization covers all areas of educational activity, therefore the electronic educational materials' creation and use is an integral part of the educational process. Their use creates a comfortable environment for learning in a youth-friendly computer environment. Evaluation system of electronic publications is based on requirements for them as well as review of functional properties compared to software capabilities and technical properties of the publication.

\section{Analysis of recent studies and publications}

The large-scale work on the creation of electronic educational resources which is being carried out at universities today requires not only forming the teacher's corresponding ICT competences, but also identifying significant criteria and creating the expert evaluation methodology of the developed educational electronic publications' quality using these criteria.

Most of Ukrainian and Western researchers' works are only devoted to electronic publications' classification study, which does not guarantee the creation of a high-quality educational resource.

In this regard research works of D. Fedasyuk, N. Hotz, N. Mikiychuk, V. Kuts and G.

${ }^{1} \mathrm{PhD}$ student.

(C) Authors. Terms and conditions of Creative Commons Attribution 4.0 International (CC BY 4.0) apply. Correspondence: Irina Kuznetsova, Kharkiv National University of Radioelectronics, Faculty of Computer Science, UKRAINE. E-mail: californashka@gmail.com. 
Kravtsov are relevant. However, there are no studies to date where quality evaluation of electronic educational publications in the ICT area is proposed.

It is important that developing international standards for information and communication of education lies in cooperation between the International Organization for Standardization and other international organizations and committees, including the International Electrotechnical Commission. International standard ISO / IEC 19796: 2005 Information technology. Learning, education and training. Quality management, assurance and metrics is the basis for description, comparison, approaches to analysis, quality management and quality assurance in this area. It serves as a tool for comparing existing approaches and their coordination using common quality model as a foundation. A key element of the standard is the Reference Framework for the description of qualitative approaches.

The ISO / IEC 19796: 2005 standard consists of three parts:

1) ISO / IEC 19796-1: 2005 - Part 1. The general approach is the first step towards the creation of a harmonized education model based on information technology;

2) ISO / IEC 19796-2 - Part 2: Harmonized Quality Model identifies tools and indicators to implement a common approach to quality;

3) ISO / IEC 19796-3 2009 - Part 3. Reference methods and metrics (which was mentioned in the previous part ISO / IEC 19796-1: 2005) extends the boundaries of standard structure for describing the approaches to quality. This is done by introducing a coherent description of recommended methods and metrics to implement the quality assurance and quality management system. Stakeholders involved in design and development use IT systems for education and learning.

But, unfortunately, most of ISO / IEC 19796: 2005 requirements only apply to standards of design quality as well as development quality and use of IT systems for education and learning quality. Therefore we can say that international standards also do not disclose the concept of the electronic educational resources quality as well as they don't include requirements to ensure it. As mentioned above, implementation of electronic educational resources into educational processes is a global trend today. One can find various methods for their quality control in the literature.

In general, their disadvantages are:

- Forming an excessive number of requirements which complicates evaluating and determining how satisfactorily assessment;

- Duplicating content requirements;

- The presented methods of monitoring and testing do not systematize requirements;

- Structural expertise methods allow evaluating the structure only, as it doesn't allow evaluating objective, methodological and scientific content of electronic educational resources;

- Complexity of estimation algorithms.

Yet, all of these methods are aimed at one goal - control of electronic educational resources conformity to specific requirements. This process is called certification in the technical regulations. This is a third-party action that proves that a properly identified product, process or service is in accordance with a specific standard or other regulatory document. 
Therefore the following is desirable:

1. For ensuring and quality control it is necessary to formulate a list of requirements for electronic educational resources and develop a methodology for internal certification of electronic educational resources at the university in accordance with existing certification rules.

2 To implement the comparability of various components of electronic educational resources, a methodology for assessing their quality level based on the theory of qualimetry as an assessment of the conformity degree of the electronic educational resource with the established requirements is necessary.

The purpose of the work is developing criteria for evaluating the quality of the educational electronic publication and determining the learning and didactic advantages as well as their implementation in the educational process in comparison with the classical school textbooks.

Tasks that need to be solved in order to achieve the goal:

- Identifying the stages of designing an electronic educational publication and requirements of electronic publication quality;

- Developing a system of indicators of an electronic educational publication quality, which integrates didactic, technical, design-ergonomic and technological characteristics;

- Evaluating electronic publications with the proposed criteria and analyzing the results.

\section{Presentation of main material E-publication development}

In structure of electronic textbook it is possible to highlight at least three components: theoretical blocks, model blocks and knowledge control blocks.

1. Theoretical blocks bear the main information load. It is better to avoid common situations when information blocks are formed using mere scan of book editions. In most of such cases not only the electronic version isn't better, but it also significantly loses to the paper version due to combination of printed text perception disadvantages and lacks of perception of static information from the monitor screen. A team of software developers together with methodologists should choose the most effective ways of presenting the learning material depending on its content. According to the authors, successful variant of the theoretical block includes voice presentation of the material accompanied by dynamic illustrations on the computer display. Ensuring internal communication in the presentation can be implemented more effectively using hypertext - the Web-based technology.

2 Model blocks - models of processes or phenomena. Models usage in the educational process is especially relevant, as we can't carry out a more or less significant real experiment. An idealized model of a real process or phenomenon is created as a program piece that makes it possible to change the parameters of this process.

Subprogram models can be created by manufacturer (internal models are embedded in the textbook while external are connected) as well as by the user of software system, e.g. by a teacher. A third option is possible - connecting models which were created by third-party manufacturers. The most widespread option to date are internal models which greatly simplifies the internal architecture of such textbooks. 
However, the negative consequences of this approach lies in the impossibility of textbook's flexible adaptation to real conditions of the educational process, which is an obvious disadvantage.

3. Knowledge control blocks include list of questions and modules for analyzing answers (rating), selecting the appropriate option for further actions (depending on the evaluation, repeating the previous topic or transiting to the next one can be chosen). The questionnaire is implemented as an opened, closed or combined test. It is obvious that all of the above related to dynamic configuration is fully applicable to the knowledge control blocks.

Summarizing the above, let's bring in the factors' diagram that helps establishing the classification of electronic publications in terms of content, technological base, complexity and other aspects.

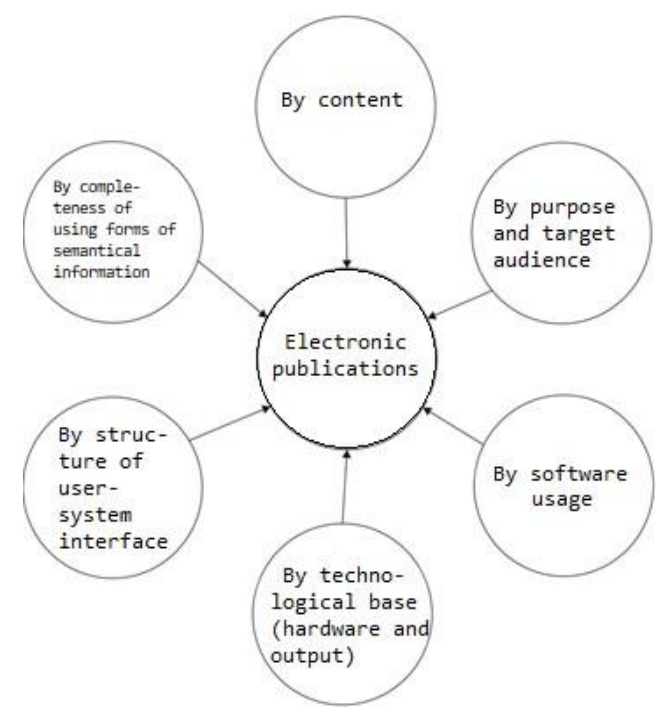

Figure 1 - Classification principles

4 Criteria for quality evaluation of electronic publication

When developing quality indicators system for online EEP, it should be taken into account that such resources do not have a "rigid" final version of structure and content and they are constantly changing throughout their life cycle while adapting to changeable requirements of the educational process and learning outcomes. Therefore, in addition to the set of indicators that are commonly used in evaluation of EEP (or electronic educational publications), indicators which allow evaluating effectiveness of the online EEP and its relevance (updating the database of reference materials, learning and methodical support, etc.) should be examined. In order to evaluate the effectiveness of an online EEP, indicators that are commonly used when evaluating web sites can be used: usability, attendance, time spent on a site, popularity / lack of demand of individual pages of a site, etc.

The system of quality evaluation indicators for online EEP by stages of the life cycle is presented in Table 1. Indicators are measured on a four-point scale, where " 3 " is a better representation of the current situation, according to the expert, and "o" is the absence of the indicator.

For accounting the significance of individual indicators, a ranking procedure based on 
one of expert methods (e.g., hierarchy analysis method, paired comparisons method etc.) can be used in the final integrated evaluation of indicators. The result of ranking is a vector of weight coefficients of indicators and groups of indicators, which will increase the accuracy of evaluation. Thus, the resulting quality evaluation will be defined as a convolution of indicators.

Table 1 - Description of EEP quality indicators

\begin{tabular}{|c|c|}
\hline Indicators & Criteria description by points \\
\hline \multicolumn{2}{|r|}{ 1 STAGE OF EEP DESIGNING } \\
\hline \multicolumn{2}{|r|}{ 1.1 Structural-Target Indicators Group } \\
\hline $\begin{array}{l}\text { 1.1.1 Presence and } \\
\text { reasonableness of the } \\
\text { purpose }\end{array}$ & $\begin{array}{l}3 \text { - Presence of a course's work program, defined requirements for the } \\
\text { pass level of competency and results of learning, expressed in the } \\
\text { form of formed competencies as a separate element of the EEP. } \\
\text { Furthermore, requirements are detailed in the methodology for } \\
\text { certain types of training work and independent work. } \\
2 \text { - Presence of a course's work program, requirements to the pass } \\
\text { level of competency and results of learning are partly determined. } \\
1 \text { - Presence of a work program. } \\
\text { o - There are no materials for this component. }\end{array}$ \\
\hline $\begin{array}{l}\text { 1.1.2 The modular } \\
\text { structure of the EEP }\end{array}$ & $\begin{array}{c}\text { 3- EEP has a clear structure corresponding to the logic of studying } \\
\text { the material as well as corresponding to the course work program. } \\
\text { The structure displays all kinds of topics and educational work to be } \\
\text { performed. } \\
2 \text { - EEP has a modular structure, but it does not fully display the logic } \\
\text { of studying the material and the composition of the work to be } \\
\text { performed. } \\
\text { - EEP is structured, but not by the modular principle of material } \\
\text { studying. } \\
\text { o- EEP is not structured. }\end{array}$ \\
\hline $\begin{array}{c}\text { 1.2.1 Scientific and } \\
\text { newness of the presented } \\
\text { educational-methodical } \\
\text { material }\end{array}$ & $\begin{array}{l}3 \text { - The high quality of the presented educational materials, EEP is } \\
\text { developed on the basis of its own scientific, educational, } \\
\text { methodological developments of the author. References to these } \\
\text { developments are presented in EEP. } \\
2 \text { - The presented material is relevant and it matches scientific and } \\
\text { technical level in the analyzed subject area. } \\
1 \text { - Materials presented in EEP are references to external works. o - } \\
\text { No material available. }\end{array}$ \\
\hline
\end{tabular}

\begin{tabular}{l|l} 
Indicators & Criteria description by points
\end{tabular}

1.2 The group of indicators that describe the content quality 


\begin{tabular}{|c|c|}
\hline $\begin{array}{l}\text { 1.2.2 Clearness and } \\
\text { understandability of } \\
\text { material }\end{array}$ & $\begin{array}{c}3 \text { - EEP materials are set out with language the target audience } \\
\text { understands, contain enough illustrative material (tables, figures } \\
\text { etc.), are structured good enough and they highlight the main ideas } \\
\text { and conclusions. } \\
2 \text { - EEP materials are presented in a language accessible to the target } \\
\text { audience, but not illustrated sufficiently, main moments are not } \\
\text { highlighted. } \\
1 \text { - Materials are presented in a manner of speech that does not match } \\
\text { the target audience and are not illustrated and structured sufficiently. } \\
\text { o - No material available. }\end{array}$ \\
\hline $\begin{array}{l}\text { 1.2.3 Problematique of } \\
\text { material presentation }\end{array}$ & $\begin{array}{c}3 \text { - Presentation of EEP materials includes practical examples, } \\
\text { explanation of complex moments, highlighting the most difficult-to- } \\
\text { understand questions, additional explanations and interdisciplinary } \\
\text { connections. } \\
2 \text { - The presented material contains practical examples, but it does not } \\
\text { display interdisciplinary connections with other fields of study. } \\
\text { - Insufficient number of examples in the educational materials of } \\
\text { EEP, interdisciplinary connections with other fields of study are not } \\
\text { displayed. } \\
\text { o- No material available. }\end{array}$ \\
\hline $\begin{array}{c}\text { 1.2.4 Sufficiency of } \\
\text { educational and } \\
\text { methodological materials }\end{array}$ & $\begin{array}{c}3 \text { - EEP contains educational and methodical materials for all types of } \\
\text { work and for all modules. } \\
2 \text { - EEP doesn't contain educational and methodological materials for } \\
\text { all the main types of work that are set out by work program of the } \\
\text { course (excluding independent work). } \\
1 \text { - EEP doesn't contain educational and methodological materials for } \\
\text { all types of work that are set out by work program of the course. } \\
\quad \text { - No material available. }\end{array}$ \\
\hline \multicolumn{2}{|c|}{ 1.3 Group of EEP's Informational, Methodological and Organizational Support Indicators } \\
\hline $\begin{array}{c}\text { 1.3.1 Taking students' } \\
\text { individual characteristics } \\
\text { into account }\end{array}$ & $\begin{array}{c}3 \text { - EEP presents different forms and variants of interim and final } \\
\text { tasks depending on their complexity level, and there is an } \\
\text { explanation to evaluation of the final results. } \\
2 \text { - EEP presents different variants of interim and final tasks } \\
\text { depending on their complexity level, and there is an explanation to } \\
\text { evaluation of the final results. } \\
\text { - EEP presents different variants of interim and final task which are } \\
\text { not differentiated by complexity levels. } \\
\text { o - EEP presents one education trajectory only. }\end{array}$ \\
\hline
\end{tabular}




\begin{tabular}{|c|c|}
\hline & $\begin{array}{c}3 \text { - EEP activates interest in obtaining new knowledge, necessitates } \\
\text { work with different types and forms of educational material, is } \\
\text { interactive and multimedia, contains interesting links and materials } \\
\text { related to the subject area and provides a system for encouraging } \\
\text { students to study successfully. }\end{array}$ \\
$\begin{array}{c}1.3 .2 \text { Increasing } \\
\text { motivation to study } \\
2 \text { - EEP presents interesting links and materials related to the subject } \\
\text { area. It also provides a system for encouraging students to study } \\
\text { successfully. } \\
1 \text { - There is a system for encouraging students to study successfully. } \\
0-\text { EEP doesn't encourage students to study. }\end{array}$ \\
\hline
\end{tabular}

\begin{tabular}{|c|c|}
\hline Indicators & Criteria description by points \\
\hline $\begin{array}{l}\text { 1.3.3 Availability and } \\
\text { sufficiency of } \\
\text { informational and } \\
\text { methodological materials } \\
\text { as well as explanations for } \\
\text { different types of } \\
\text { educational activities }\end{array}$ & $\begin{array}{c}3 \text { - EEP provides informational and methodological instructions to all of } \\
\text { EEP modules with explanation of right order of studying the material as } \\
\text { well as explanations of tasks' arrangement, of work with literature etc. } \\
\text { Materials are presented as separate elements of the EEP. } \\
2 \text { - EEP provides informational and methodological instructions to } \\
\text { some of the modules and tasks of EEP, but they are marked as } \\
\text { separate elements of EEP. } \\
\text { 1 - EEP provides informational and methodological instructions for } \\
\text { EEP's individual elements studying that are not marked as separate } \\
\text { elements of EEP. } \\
\text { o - Informational and methodological materials are not presented. }\end{array}$ \\
\hline $\begin{array}{l}\text { 1.3.4 Sufficiency of } \\
\text { supporting material }\end{array}$ & $\begin{array}{c}3 \text { - The list of literature, a glossary and links to Internet sources are } \\
\text { presented in the EEP. } \\
2 \text { - The list of literature and a glossary are presented in EEP. } \\
1 \text { - The list of literature is presented in EEP. } \\
\text { o - Additional materials are not presented. }\end{array}$ \\
\hline \multicolumn{2}{|r|}{ 1.4. Group of indicators that characterize EEP control functions } \\
\hline $\begin{array}{l}\text { 1.4.1 Variet } \\
\text { and self-co }\end{array}$ & $\begin{array}{c}3 \text { - Different types and forms of intermediate and final control, } \\
\text { including interactive forms of control, are presented in the } \\
\text { corresponding LMS system (essays, tests, seminars) which is used in } \\
\text { EEP. Control forms display the specifics of tasks. } \\
2 \text { - Different types and forms of interim and final control are used in } \\
\text { EEP, but EEP still lacks interactive forms. } \\
\text { - The forms of control used in EEP are of the same type, they do not } \\
\text { display the specifics of tasks. Interactive forms of control are not } \\
\text { used. } \\
\text { o- Such component is not presented. }\end{array}$ \\
\hline $\begin{array}{l}\text { 1.4.2 Diagnosis of } \\
\text { learning outcomes }\end{array}$ & $\begin{array}{c}\text { 3 - Diagnosis of knowledge level at the beginning, various types of } \\
\text { tasks' completion results and the final control's results is carried out } \\
\text { in the EEP. } \\
2 \text { - Diagnosis of certain types of tasks' completion results, as well as } \\
\text { the final control's results is carried out in EEP. } \\
1 \text { - Diagnosis of the final control's results is carried out in EEP. } \\
\text { O - Such component is not presented. }\end{array}$ \\
\hline
\end{tabular}




\begin{tabular}{|c|c|}
\hline $\begin{array}{c}1.4 \cdot 3 \text { Availability of } \\
\text { control and measurement } \\
\text { materials }\end{array}$ & $\begin{array}{l}3 \text { - Sufficient supervisory tasks for understanding and mastering of } \\
\text { educational material, the number of test tasks exceeds } 200 \text { units. } \\
2 \text { - Sufficient supervisory tasks for understanding and mastering of } \\
\text { educational material, the number of test tasks exceeds } 100 \text { units. } \\
\text { - EEP only has test tasks and their number exceeds } 100 \text { units. } \\
\text { o - Control and measurement materials are not sufficient. }\end{array}$ \\
\hline \multicolumn{2}{|r|}{2 STAGE OF EEP REALIZATION } \\
\hline \multicolumn{2}{|r|}{ 2.1 Group of design-ergonomic indicators } \\
\hline $\begin{array}{l}\text { 2.1.1 Quality of text } \\
\text { material }\end{array}$ & $\begin{array}{c}3 \text { - High quality of text material. Colors, fonts and similar methods of } \\
\text { text highlighting in accordance with the logic of presentation. Text } \\
\text { design is coherent, the text is readable, and possibility of } \\
\text { personalization is provided. } \\
2 \text { - Good quality design of text material, text design is coherent and } \\
\text { text is readable. } \\
\text { 1 - Low quality design of text material, text is not structured. } \\
\text { o - Text is unreadable. }\end{array}$ \\
\hline
\end{tabular}

\begin{tabular}{|c|c|}
\hline Indicators & Criteria description by points \\
\hline $\begin{array}{l}\text { 2.1.2 Quality and } \\
\text { sufficiency of graphic } \\
\text { images, audio and video } \\
\text { material }\end{array}$ & $\begin{array}{l}3 \text { - High quality of graphic, audio and video content design. EEP has } \\
\text { sufficient quantity of such content for students to explore. } \\
2 \text { - Good quality of graphic, audio and video content design. EEP has } \\
\text { insufficient or excessive quantity of such content. } \\
1 \text { - Low quality of graphic, audio and video content design. } \\
\text { o - Materials are presented. }\end{array}$ \\
\hline \multicolumn{2}{|r|}{ 2.2 Group of technical indicators } \\
\hline 2.2.1 Links workability & $\begin{array}{l}3 \text { - All of EEP links are functioning. } \\
2 \text { - EEP contains insignificant number of invalid links. } \\
1 \text { - EEP contains significant number of invalid links. } \\
\text { o - Most of EEP links are invalid. }\end{array}$ \\
\hline Indicators & Criteria description by points \\
\hline $\begin{array}{l}\text { 2.2.2 Convenience of } \\
\text { materials presentation } \\
\text { based on using different } \\
\text { electronic formats }\end{array}$ & $\begin{array}{c}3 \text { - Different formats are available for viewing educational materials. } \\
\text { EEP materials are presented using modern free circulating formats, } \\
\text { their viewing does not require additional software (or its installation } \\
\text { is not hard and a corresponding manual is provided). } \\
2 \text { - EEP materials are presented using modern free circulating } \\
\text { formats, their viewing does not require additional software (or its } \\
\text { installation is not hard and a corresponding manual is provided). } \\
1 \text { - While viewing some of EEP materials problems related to selected } \\
\text { format of presentation may arise. } \\
\text { o - Materials are visible. }\end{array}$ \\
\hline \multicolumn{2}{|r|}{3 STAGE OF EEP EXPLOITATION } \\
\hline \multicolumn{2}{|r|}{ 3.1 Indicators of EEP supporting } \\
\hline
\end{tabular}




\begin{tabular}{|c|c|}
\hline $\begin{array}{l}\text { 3.1.1 Journaling of } \\
\text { students' academic } \\
\text { achievements }\end{array}$ & $\begin{array}{c}3 \text { - All of students' works (including tests and other types of control) } \\
\text { are checked in time. Schedule of checkpoints is presented. Records } \\
\text { are kept in a grade book and students have access to it. } \\
2 \text { - Tests are the only checkpoints. Records are kept in a grade book. } \\
\text { Schedule of checkpoints is presented. } \\
1 \text { - Tests are the only checkpoints. Records are kept in a grade book. } \\
\text { o - Checkpoints are not defined. }\end{array}$ \\
\hline Indicators & Criteria description by points \\
\hline $\begin{array}{l}\text { 3.1.2 Support of feedback } \\
\text { with students (sending } \\
\text { messages and answering } \\
\text { messages as well as } \\
\text { informing about } \\
\text { upcoming events) }\end{array}$ & $\begin{array}{l}3 \text { - Students are informed about upcoming events in time (via the } \\
\text { forum or sending personal messages). Teacher answers students' } \\
\text { questions and moderates the forum. } \\
2 \text { - Teacher answers students' questions and informs them. } \\
1 \text { - Teacher answers students' questions. } \\
\text { o - Teacher does not support feedback. }\end{array}$ \\
\hline
\end{tabular}

\section{Results of experimental work}

The considered indicators of EEP quality evaluation were tested in the educational process of Kharkiv comprehensive school № 131 for evaluating online EEP, which are electronic educational-methodical sets of disciplines. 15 online EEPs with physics and astronomy as subjects were evaluated (Figures 2.3 show the grade point averages by groups of indicators) by teachers and students of school as experts.

This technique revealed the most problematic aspects of online EEPs' creation and exploitation: the lack of organizational and methodological support for studying EEP and ways of encouraging students to study (the average score for this component is 1.38), as well as low quality of EEP support (this component's average score is 1.63).

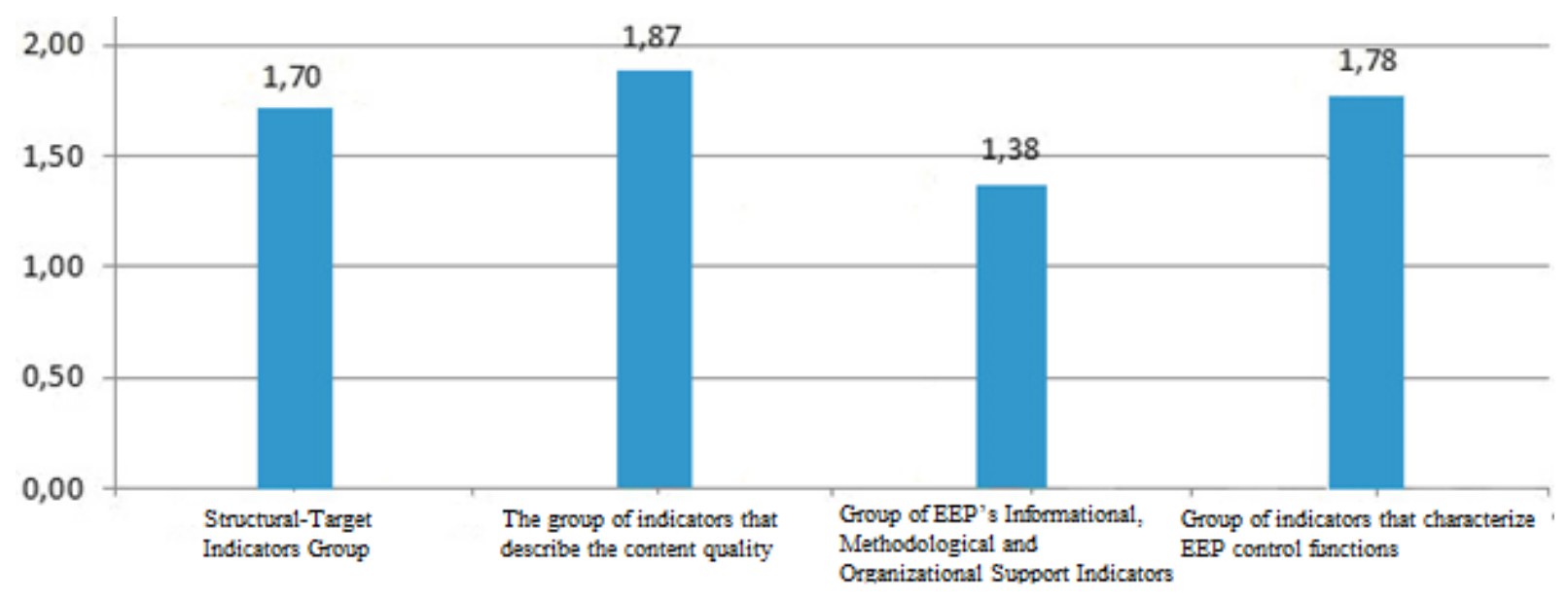

Figure 2.1 - Average marks by groups of indicators 
I. Kuznetsova \& O. Vovk - Technology of Educational Electronic Publications' Quality Evaluation

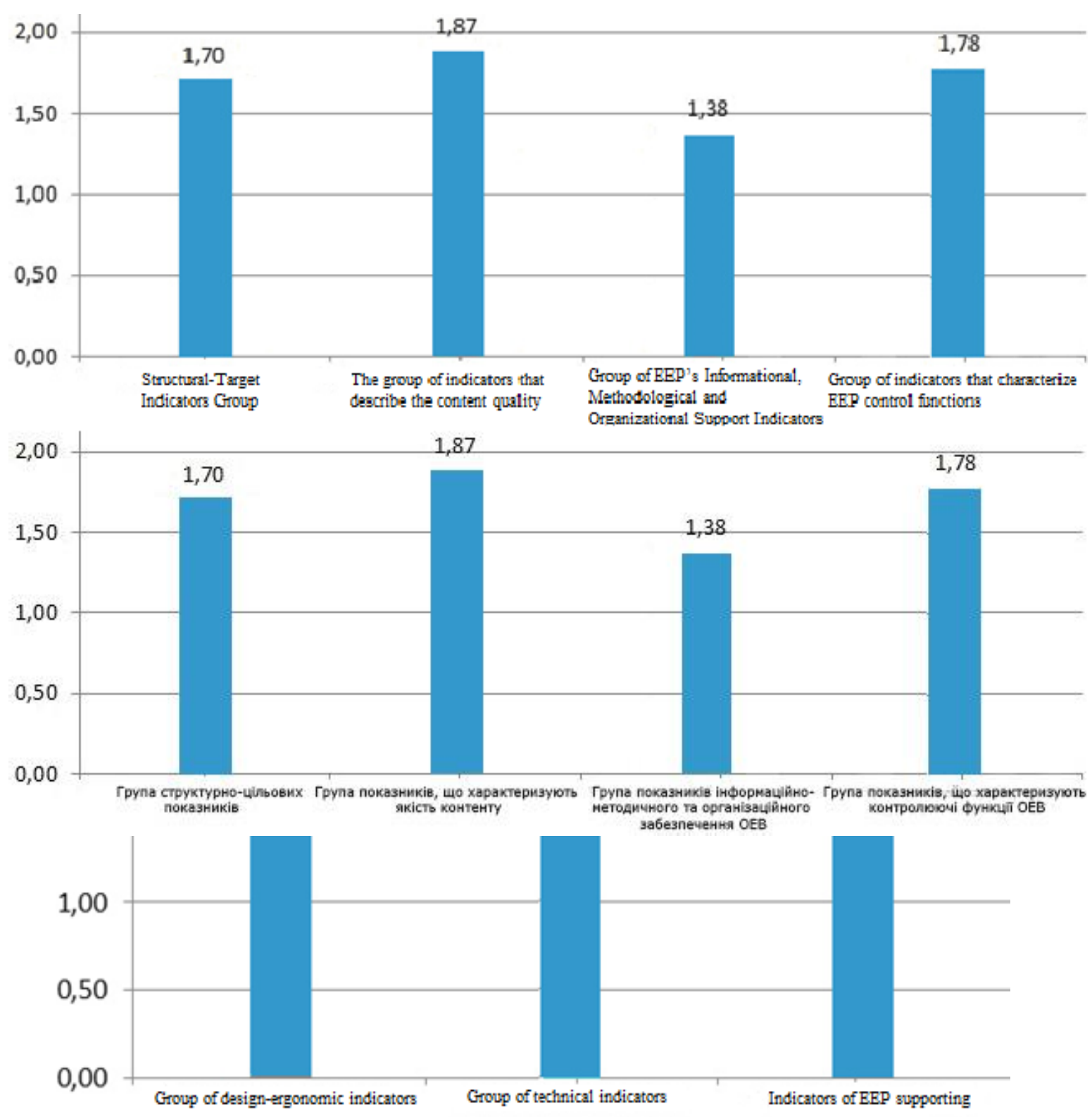

Figure 2.2 - Average marks by groups of indicators

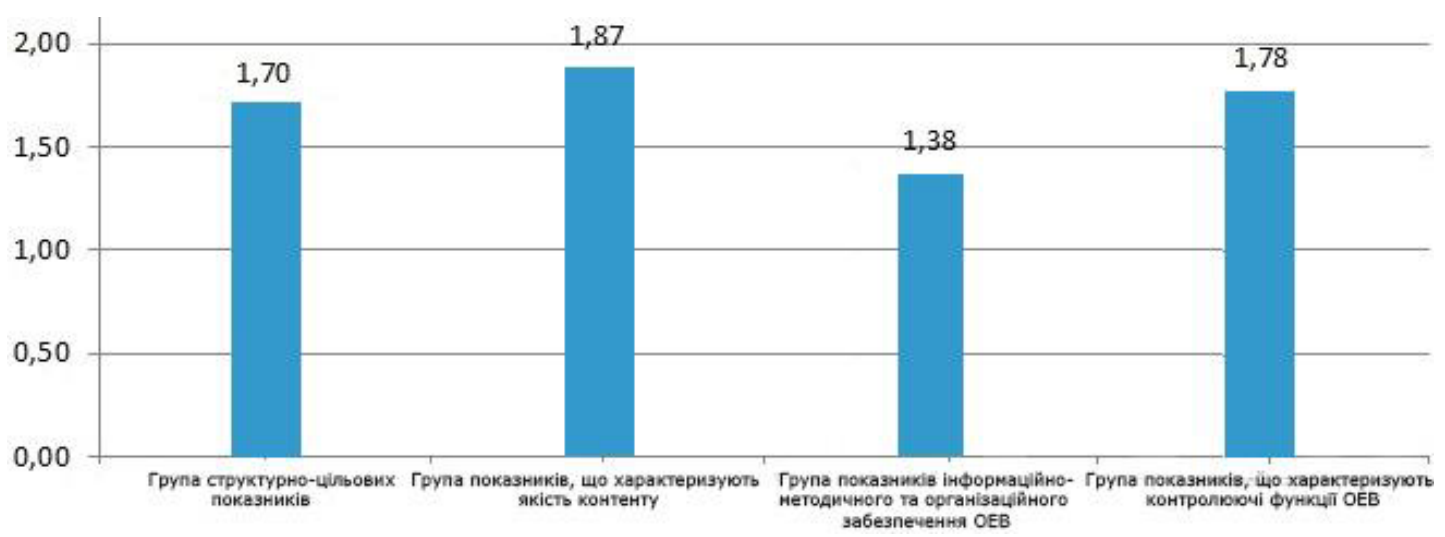

Figure 2.3 - Average marks by groups of indicators 


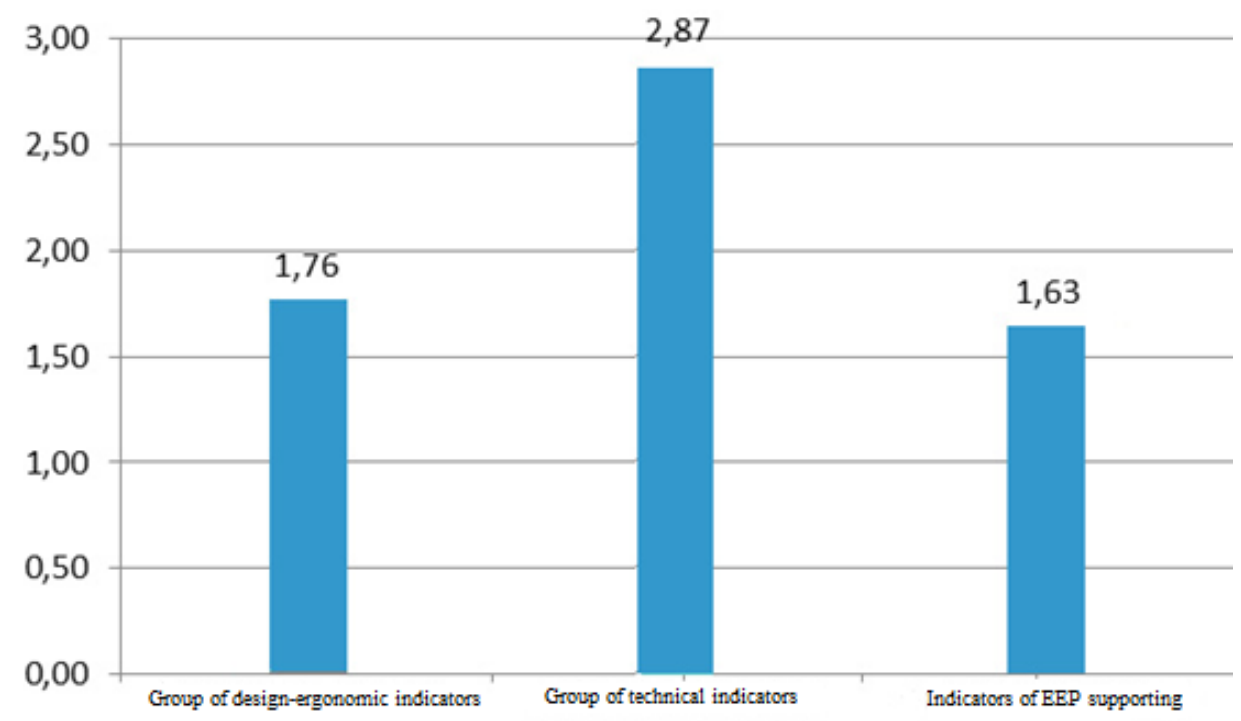

Figure 3 - Average marks by groups of indicators

Analyzing the results of experimental work by components separately brings us to the following conclusions:

a) EEP's informational and methodological materials for studying course quantity is insufficient or zero. EEP doesn't encourage students to study;

b) EEP is being developed separately from the course's work program. Therefore, structure and content of EEP and work program requirements are mismatched;

c) Teachers do not structure EEP thoroughly and in modules. They lay out theoretical and practical parts separately;

d) insufficiency of interactive forms for learning and control;

e) Most teachers consider EEP as a way of providing educational material. evidenced by:

However, they don't consider EEP as interactive communication with students as

1) Low EEP attendance ("reduction" of material which brings to irrelevance of the course);

2) Insufficient relevance of interactive forms of training and control. Task checking and journaling of students' academic achievements are conducted outside the LMS system;

3) Low level of information support for students in education.

As a result, one of the main areas suitable for improving the quality of student learning is electronic learning which is focused on active independent work of students and includes using ICT and multimedia in both traditional and distance learning.

\section{Conclusion}

The quality of e-learning depends directly on the EEPs' quality, the relevance and correctness of the information provided in EEP, as well as the possibilities of organizing control and self-control, communication, and complying with health-caring education technologies.

The presented system of indicators and criteria, as well as a technique for evaluating the quality of online EEP allows: 
(a) Evaluating the components and analyzing the quality of courses. Depending on the results of evaluation the expert group or author may take a balanced and reasoned decision on accepting, rejecting or revising the proposed publication;

(b) Summarizing the results and highlighting the main problem areas of EEP development throughout its life cycle. The results will enhance the quality of EEPs. This set of requirements for EEP's functional properties implementation will give users the fullest opportunity possible to use the software properties of the shell in which the EEP will be reproduced;

(c) Using the evaluation results to make appropriate management decisions on improving the EEP's quality.

In order to make a decision on the general rating of the publication it is desirable to use the following criteria:

1) Score between 2.5 and 3 is high. No corrections are required and EEP can be used in the educational process;

2) Score between 2 and 2.5 is higher than the average. Before using EEP in the educational process, it is necessary to finalize the individual details;

3) Score between 1.5 and 2 is average. It is necessary to finalize the functional properties of EEP and send it back for reviewing;

4) Score between 1 and 1.5 is below average. EEP requires serious work on errors and flaws;

5) Score between 0 and 1 is low. EEP is not suitable for training.

\section{Acknowledgements}

This research did not receive any specific grant from funding agencies in the public commercial, or not-for-profit sectors.

The authors declare no competing interests.

\section{References}

Shalkina, T. N. (2013). A model for a comprehensive assessment of the quality of electronic educational publications and resources.

Fedyukin, V. K. (2007). Methods of parametric assessment of product quality. Quality, innovation, education. 5, 33-38.

Osin, A. V. (2005). Multimedia in education: The context of informatization. Moscow: Publishing Service Agency.

Kuznetsova, I. A. (2018). Technologies for the Evaluation of High-Level Electronic Vidan. In: O. V. Vovk \& I. A. Kuznetsova (Eds.), III International Conference on Science and Technology Conference "Poligraphic, Multimedia and Web-Technology" (pp. 191-193). Jan 17-19, M. Lviv. 